\title{
Continuous-flow ventricular assist device support in children: A paradigm change
}

\author{
Iki Adachi, MD
}

From the Departments of Surgery and Pediatrics, Baylor College of Medicine, Houston, Tex.

Received for publication Nov 8, 2016; revisions received Jan 17, 2017; accepted for publication Feb 2, 2017; available ahead of print June 20, 2017.

Address for reprints: Iki Adachi, MD, 6621 Fannin St, 19345H, Houston, TX 77030 (E-mail: ixadachi@ texaschildrens.org).

J Thorac Cardiovasc Surg 2017;154:1358-61

$0022-5223 / \$ 36.00$

Copyright (c) 2017 by The American Association for Thoracic Surgery

http://dx.doi.org/10.1016/j.jtcvs.2017.02.082

There has been a substantial increase in the use of continuous-flow ventricular assist devices (VADs) over the last decade. In the adult population, continuous-flow devices completely dominate the field, representing more than $90 \%$ (12,030 of 13,286 primary implants for left heart support) of the durable VADs implanted between 2006 and 2014. ${ }^{1}$ This phenomenon is driven primarily by improved complication profiles and durability of continuous-flow VADs compared with pulsatile VADs. With ongoing device miniaturization, enthusiasm has been growing among pediatric physicians for the use of continuous-flow VADs in children. According to the first PediMACS report, ${ }^{2}$ approximately one-half $(54 \% ; 109$ of 200) of the long-term devices registered are continuous-flow devices. ${ }^{2}$

With the encouraging results recorded to date, the use of continuous-flow devices in the pediatric population is rapidly increasing. Continuous-flow VADs compose $62 \%$ (179 of 291) of all durable VAD implants in the PediMACS 2016 third quarter report. ${ }^{3}$ In this commentary, I describe the current state of pediatric continuous-flow VAD support, and discuss perspectives regarding its future direction.

\section{BEYOND PULSATILE DEVICES}

There is no doubt that continuous-flow VAD technology has had a profoundly positive impact on the outcomes of VAD support in the adult population. ${ }^{4}$ It is plausible that nearly adult-sized adolescents would have equally excellent outcomes with continuous-flow VADs that were intended for use in adults ${ }^{5}$; however, it is premature to assume that continuous-flow VADs would have a similar impact across the spectrum of body sizes in the pediatric population. Although anecdotal reports with continuous-flow VADs in children are rather encouraging, careful evaluation of available outcomes data is warranted before definitive conclusions can be drawn. Nonetheless, whether smaller children will also experience comparable outcomes with adult-sized continuous-flow VADs remains to be seen.

A major concern with the use of continuous-flow VADs in smaller children is a patient-device size mismatch, ${ }^{6}$ particularly because all currently available continuous-

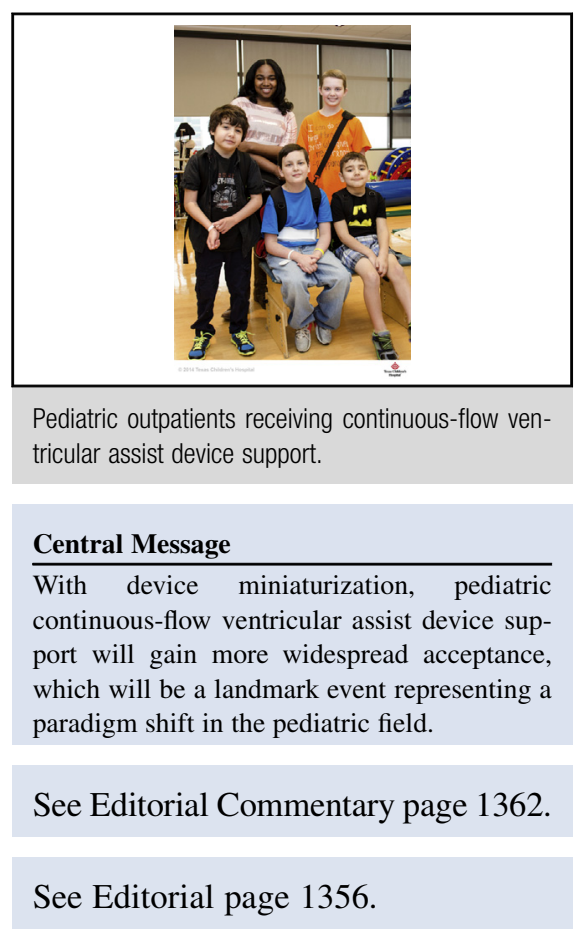

flow VADs are designed for adult patients. A recent multi-institutional study evaluating outcomes after implantation of the HVAD system (Medtronic, Minneapolis, Minn) in children with a body surface area of $<1.0 \mathrm{~m}^{2}$ showed a favorable survival rate, but with a high incidence of complications, including pump thrombosis. ${ }^{7}$ Conway et $\mathrm{al}^{8}$ conducted a world-wide survey evaluating the outcome of the HVAD use in children. This study, involving 250 patients from 35 sites in 12 countries, demonstrated a tendency toward poorer outcomes in smaller children; the mortality rate at age $<12$ months was $15.6 \%$ (95\% confidence interval [CI], 3.96\%-28.93\%) in children weighing $<25 \mathrm{~kg}$ and $7.6 \%$ (95\% CI, 6.2\%-28.9\%) $>25 \mathrm{~kg}$. Although the observed difference in mortality did not reach statistical significance, it warrants close attention from a clinical standpoint. Anecdotally, it is known that both weight and the shape of the chest wall are important factors in successful VAD implantation in children; a smaller child with a broad chest may be a more suitable candidate than a larger child with a narrow chest. Evaluation by "virtual implantation," such as that used for total artificial heart implantation, ${ }^{9}$ may provide useful guidance in determining compatibility.

Nonetheless, the smaller the heart, the more significant the size mismatch between the patient and the device. 
Development of pediatric-specific continuous-flow VADs, such as the Infant Jarvik, ${ }^{10}$ may alleviate inherent size mismatch issues. The latest iteration of the pediatricspecific continuous-flow VAD, renamed the Infant Jarvik 2015, was granted conditional approval for Investigational Device Exemption by the US Food and Drug Administration on September 30, 2016. The Infant Jarvik 2015 has an outer diameter of $15 \mathrm{~mm}$ and an overall length of $55 \mathrm{~mm}$, approximately the size of an AA battery. The operating speed range of the Infant Jarvik 2015 is 10,000 to $18,000 \mathrm{rpm}$, which produces a flow range of 0.5 to $3.0 \mathrm{~L} /$ minute at a differential pressure of $45 \mathrm{mmHg} .{ }^{11}$ Whether or not continuous-flow VAD support is genuinely beneficial for small children will be ascertained during the PumpKIN (Pumps for Kids, Infants, and Neonates) trial, a prospective 2-arm randomized controlled trial with a randomization ratio of $1: 1$ between the Infant Jarvik 2015 and the control device, the Berlin Heart EXCOR (Berlin Heart Inc, The Woodlands, Tex). Patients eligible for the trial will be limited to those with 2ventricle circulation and weighing between 8 and $20 \mathrm{~kg}$. The sample size will be 44 per arm, and there will be approximately 22 sites for the trial. The trial is now scheduled to begin in early 2017 .

Based on experience with the chronic animal model, ${ }^{7}$ I believe that the Infant Jarvik device will properly fit the patients included in the trial. As experience is gained over the duration of the trial, application of this device may be expanded further, even to children weighing $<8 \mathrm{~kg}$.

\section{BEYOND IN-HOSPITAL MANAGEMENT}

Among all the proposed advantages of continuous-flow VADs over the Berlin EXCOR, the potential for home discharge emerges as the most significant factor for patients and caregivers. Outpatient management of children with continuous-flow VADs has been shown to be feasible, ${ }^{2,12-14}$ although only $45 \%$ of pediatric patients with continuous-flow VAD are discharged, according to the PediMACS registry. ${ }^{2}$ Nonetheless, with maturation of the pediatric field, outpatient management will become routine rather than the exception. Being at home certainly improves the quality of life of patients with a continuousflow VAD. Equally important is the fact that outpatient management enables "true" long-term support for pediatric patients. Although the EXCOR is considered a long-term device, the duration of support with the EXCOR typically ranges between several weeks to months. In the prospective Berlin Heart EXCOR trial, the median duration of support were 28 days in smaller children (body surface area $<0.7 \mathrm{~m}^{2}$ ) and 43 days in larger children. ${ }^{15}$

Even though the reason for the relatively short duration of support was likely multifactorial, a major determinant of this would be the clinician's apprehension that once the VAD is placed, it must be explanted as quickly as possible (as opposed to when clinically optimal) if potential complications are to be avoided. In other words, patients with the pulsatile VAD support are oftentimes compelled to 'rush' into transplantation. The clinical focus in such circumstances is primarily whether patients survive to transplantation.

\section{BEYOND SURVIVAL}

Although continuous-flow VADs are currently managed similarly (ie, rushing approach) at most pediatric centers, this may soon change as pediatric centers gain experience, and confidence, in the management of continuous-flow VADs. At Texas Children's Hospital, we have adopted a policy in which the patient is designated as "inactive" on the transplant wait list for at least 3 months after initiation of continuous-flow VAD support. ${ }^{16}$ The rationale behind this practice lies in the patient's perioperative state of health; because most children with severe heart failure are profoundly deconditioned by the time of VAD implantation, a postoperative "grace period" affords protected opportunities for both physical and psychological recovery after initiation of VAD support. In other words, VAD support is intended not only to improve survival, but also to improve patients' overall status and thus increase their suitability for transplantation.

An additional, and possibly more important, advantage of such a "waiting" approach is that the grace period provides an opportunity to assess the myocardium for possible functional recovery. ${ }^{17}$ Despite extensive research in both the basic science and clinical arenas, currently there are no tests to reliably predict in whom the heart will recover. In the absence of definitive predictors, the only way to confirm the irreversibility of native cardiac function would be to provide sufficient time for the heart to rest. Anecdotal experiences indicate that chronically failing hearts begin to show gross signs of recovery typically after at least a couple of months of myocardial decompression. ${ }^{17}$ Considering this, it is quite possible that some potentially recoverable native hearts are prematurely replaced if the current standard "rushing" approach (ie, to perform transplantation as soon as a donor heart becomes available after initiation of VAD support, to avoid complications) is strictly adhered to. According to the PediMACS report, approximately $50 \%$ of children with continuous-flow VAD support undergo heart transplantation within 3 months of initiation of VAD support. ${ }^{2}$ This may explain why the rate of cardiac recovery is even lower in pediatric patients $(0.6 \%$ in the PediMACS registry $\left.{ }^{18}\right)$ than in adult patients $(1 \%$ in the INTERMACS registry ${ }^{1}$ ), despite the ample anecdotal evidence suggesting that the younger the patient, the greater the likelihood of cardiac recovery. ${ }^{19}$

\section{BEYOND TRANSPLANTATION}

The durability of continuous-flow VADs also may make it feasible to provide VAD support as a chronic therapy in 
children who are not good candidates for transplantation (so-called "destination" therapy). Current experience with VAD support intended as destination therapy in the pediatric population is limited, given that candidacy for destination support is restricted mostly to rare skeletal myopathies, such as Duchenne disease. ${ }^{20,21}$ If the indications for such use are expanded to include patients with congenital heart disease, particularly those with singleventricle physiology (as discussed below), the demand for destination support may be substantially increased. Nonetheless, controversy exists as to whether the descriptor "destination" is appropriate for the pediatric population. Proponents of this notion would submit that young patients have a great capacity for positive change, and thus current barriers to transplantation during childhood might not necessarily preclude future transplantation candidacy. Prolonged continuous-flow VAD support during adolescence and young adulthood, facilitated by the feasibility of outpatient management, grants such patients the luxury of time to become fully cognizant of the possible consequence of destination VAD therapy and possibly make positive changes to become a suitable candidate. Given the possibility of such changes during the course of long-term VAD support, the pediatric field may reach a point where the goal of support does not necessarily need to be determined at the time of VAD implantation, but rather VAD support may be accepted as a stand-alone therapy for medically resistant heart failure requiring hospitalization, akin to a pacemaker implant in pacing-dependent patients.

In our program, several adolescents and young adult patients are currently receiving prolonged VAD support (the longest for $>5$ years) who are currently considered noncandidates for transplantation because of various psychosocial issues. However, these issues possibly may be modifiable with age, and these patients may become suitable candidates in the future. In this context, VAD support is used to provide sufficient time to achieve emotional and behavioral maturation, which would eventually determine their survivability (ie, bridge to maturation). Providing prolonged VAD support in adolescents also may be supported by the fact that adolescents have the poorest post-transplantation outcomes of all age groups. Bypassing such an unfavorable period for transplantation with prolonged VAD support may be a reasonable approach.

\section{BEYOND NORMALLY STRUCTURED HEARTS}

Patients with failing single-ventricle physiology represent a growing population for whom medicine does not yet have realistic solutions. Given the palliative nature of the interventions to ameliorate single-ventricle physiology, the possibility exists that all single-ventricle patients, including those who thrive after the Fontan procedure, will eventually fail. From the standpoint of VAD support, this population presents the greatest challenge owing to complexities inherent to single-ventricle anatomy and physiology. Experience in VAD support for single-ventricle physiology is limited. In reviewing the outcomes of the Berlin Heart EXCOR study in North America, Weinstein et $\mathrm{al}^{22}$ found significantly worse survival in patients with a single ventricle compared with those with biventricular physiology $(42 \%$ vs $73 \%)$ despite the lack of significance differences in baseline demographic parameters. ${ }^{22}$ The most striking finding is the significant difference in survival depending on the stage of single-ventricle palliations at which EXCOR support was implemented. In contrast to the dismal outcome in neonatal palliative surgery group (ie, stage I, $11 \%$ survival), survival for Glenn (ie, stage II, 58\%) and Fontan physiology (ie, stage III, $60 \%$ ) were more favorable with the EXCOR device. In fact, these results were superior to what had previously been reported regarding the outcomes of extracorporeal membrane oxygenation support for single-ventricle physiology (Glenn, $41 \%$ survival $^{23}$; Fontan, 35\% survival $^{24}$ ).

Because Fontan circulation can fail for multiple reasons, such as systolic or diastolic dysfunction, elevated pulmonary vascular resistance, or both, ${ }^{9}$ careful determination of the exact cause of circulatory failure is necessary. If systolic dysfunction is the predominant cause of circulatory failure, then VAD support for the failing systemic ventricle likely will improve hemodynamics. The type of VAD used may make a difference in this particular group of patients. The theoretical advantages of continuous-flow VAD over pulsatile VAD in single-ventricle physiology have been described previously. ${ }^{25}$ Pulsatile VAD decompresses the failing systemic ventricle only during pump diastole. Because the pulmonary circulation typically carries "passive flow" via cavo-pulmonary connection(s), the circulation would be more efficient with continuous decompression of the systemic ventricle with continuousflow VADs compared with intermittent decompression with pulsatile VADs. Several reports have described the successful use of an adult-sized continuous-flow VAD (eg, HeartMate II) in larger children with failing Fontan circulation. ${ }^{26}$ As a result of device miniaturization, smaller continuous-flow VADs, such as the HVAD device, are now being used in smaller Fontan recipients and even in patients with failing Glenn physiology. ${ }^{13}$

VAD support may serve not only to improve the efficiency of failing single-ventricle circulation, but also to reliably promote the patient through the multiple stages of palliation. To illustrate, one may wonder why a patient with Glenn circulation (with primarily systolic dysfunction) would not undergo Fontan completion if the failing ventricle were adequately supported with a VAD. We previously reported a case of a 6-year-old male with a functional single ventricle of right ventricular morphology with failing Glenn circulation. ${ }^{27}$ Instead of simply implanting a continuous-flow VAD, we concomitantly created an 
extracardiac Fontan channel to eliminate the deleterious effect of chronic cyanosis. With improved cardiac output in the setting of normal oxygen saturation level, the patient's exercise capacity improved dramatically. Again, the emphasis is not just on simply keeping the patient alive until a donor organ becomes available; rather, attention is refocused on overall health beyond survival, which may eventually affect transplantation candidacy and even posttransplantation outcome. This is the time we, as physicians in the pediatric field, need to adjust our mind set and aim to achieve much more than survival. We must be confident in the knowledge that the field is maturing rapidly enough to accommodate the continually evolving treatment philosophies. The increasing use of continuous-flow VADs in children will be remembered as a landmark event of such a paradigm shift.

\section{SUMMARY}

With ongoing device miniaturization, the era of pediatric continuous-flow VAD support has begun. The emergence of the Infant Jarvik 2015, the first continuous-flow device specifically designed for small children, may further accelerate the trend toward the use of continuous-flow devices in children. Pediatric VAD support will continue to evolve as the pediatric mechanical circulatory support arena matures. The popularization of continuous-flow devices will be a landmark event that would represent a paradigm change in this field.

\section{Conflict of Interest Statement}

Dr Adachi serves as a consultant and proctor for Berlin Heart Inc. and HeartWare Inc, and as a consultant for the New England Research Institute related to the PumpKIN trial.

\section{References}

1. Kirklin JK, Naftel DC, Pagani FD, Kormos RL, Stevenson LW, Blume ED, et al. Seventh INTERMACS annual report: 15,000 patients and counting. J Heart Lung Transplant. 2015;34:1495-504.

2. Rossano JW, Lorts A, VanderPluym CJ, Jeewa A, Guleserian KJ, Bleiweis MS, et al. Outcomes of pediatric patients supported with continuous-flow ventricular assist devices: a report from the Pediatric Interagency Registry for Mechanical Circulatory Support (PediMACS). J Heart Lung Transplant. 2016; 35:585-90.

3. PediMACS. Pediatric Registry for Mechanically Assisted Circulatory Support. Quarterly Statistical Report. 3rd Quarter. Available at: https://www.uab.edu/ medicine/intermacs/images/Federal_Quarterly_Report/Pedimacs___Federal_ Partners_Report_2016_Q3.pdf. Accessed January 17, 2017.

4. Slaughter MS, Rogers JG, Milano CA, Russell SD, Conte JV, Feldman D, et al. Advanced heart failure treated with continuous-flow left ventricular assist device. N Engl J Med. 2009;361:2241-51.

5. Cabrera AG, Sundareswaran KS, Samayoa AX, Jeewa A, McKenzie ED, Rossano JW, et al. Outcomes of pediatric patients supported by the HeartMate II left ventricular assist device in the United States. J Heart Lung Transplant. 2013:32:1107-13.

6. Adachi I, Burki S, Zafar F, Morales DL. Pediatric ventricular assist devices. J Thorac Dis. 2015;7:2194-202.
7. Miera O, Kirk R, Buchholz H, Schmitt KRL, VanderPluym C, Rebeyka IM, et al. A multicenter study of the HeartWare ventricular assist device in small children. J Heart Lung Transplant. 2016;35:679-81.

8. Conway J, Miera O, Henderson HT, VanderPluym C, Buchholz H, Fenton M, et al. Global experience with the Heartware HVAD in pediatric patients: a preliminary analysis. J Heart Lung Transplant. 2016;35:679-81.

9. Moore RA, Madueme PC, Lorts A, Morales DL, Taylor MD. Virtual implantation evaluation of the total artificial heart and compatibility: beyond standard fit criteria. J Heart Lung Transplant. 2014;33:1180-3.

10. Adachi I, Burki S, Horne D, Costas GG, Spangler T, Jarvik R, et al. The miniaturized pediatric continuous flow device: preclinical assessment in the chronic sheep model. J Thorac Cardiovasc Surg. 2017;154:291-300.

11. Baldwin JT, Adachi I, Teal J, Almond CA, Jaquiss RD, Massicotte MP, et al Closing in on the PumpKIN trial of the Jarvik 2015 Ventricular Assist Device. Semin Thorac Cardiovasc Surg Pediatr Card Surg Annu. 2017;20:9-15.

12. Conway J, VanderPluym C, Jeewa A, Sinnadurai S, Schubert A, Lorts A. Now how do we get them home? Outpatient care of pediatric patients on mechanical circulatory support. Pediatr Transplant. 2016;20:194-202.

13. Adachi I, Jeewa A, Burki S, McKenzie ED, Fraser CD Jr. Outpatient management of a child with bidirectional Glenn shunts supported with implantable continuous-flow ventricular assist device. J Heart Lung Transplant. 2016;35: 688-90.

14. Schweiger M, Vanderpluym C, Jeewa A, Canter CE, Jansz P, Parrino PE, et al Outpatient management of intra-corporeal left ventricular assist device system in children: a multi-center experience. Am J Transplant. 2015;15: 453-60.

15. Fraser CD Jr, Jaquiss RD, Rosenthal DN, Humpl T, Canter CE, Blackstone EH et al. Prospective trial of a pediatric ventricular assist device. N Engl J Med. 2012; 367:532-41.

16. Adachi I, Fraser CD Jr. Ventricular assist device for infants and children: state of the art and future. In: Gravlee GP, Davis RF, eds. Cardiopulmonary Bypass and Mechanical Support: Principles and Practice. 4th ed. Philadelphia, PA: Lippincott Williams Wilkins; 2016:729-42.

17. Drakos SG, Wever-Pinzon O, Selzman CH, Gilbert EM, Alharethi R, Reid BB et al. Magnitude and time course of changes induced by continuous-flow left ventricular assist device unloading in chronic heart failure: insights into cardiac recovery. J Am Coll Cardiol. 2013;61:1985-94.

18. Blume ED, Rosenthal DN, Rossano JW, Baldwin JT, Eghtesady P, Morales DL, et al. Outcomes of children implanted with ventricular assist devices in the United States: first analysis of the Pediatric Interagency Registry for Mechanical Circulatory Support (PediMACS). J Heart Lung Transplant. 2016; 35:578-84.

19. Weia BC, Adachi I, Jacot JG. Clinical and molecular comparison of pediatric and adult reverse remodeling with ventricular assist devices. Artif Organs. 2015;39: 691-700.

20. Perri G, Filippelli S, Adorisio R, Iacobelli R, Iodice F, Testa G, et al. Left ven tricular assist device as destination therapy in cardiac end-stage dystrophinopathies: midterm results. J Thorac Cardiovasc Surg. 2017;153:669-74.

21. Ryan TD, Jefferies JL, Sawnani H, Wong BL, Gardner A, Del Corral M, et al Implantation of the HeartMate II and HeartWare left ventricular assist devices in patients with Duchenne muscular dystrophy: lessons learned from the first applications. ASAIO J. 2014;60:246-8.

22. Weinstein S, Bello R, Pizarro C, Fynn-Thompson F, Kirklin J, Guleserian K, et al The use of the Berlin Heart EXCOR in patients with functional single ventricle. $J$ Thorac Cardiovasc Surg. 2014;147:697-704; discussion 704-5.

23. Jolley M, Thiagarajan RR, Barrett CS, Salvin JW, Cooper DS, Rycus PT, et al Extracorporeal membrane oxygenation in patients undergoing superior cavopulmonary anastomosis. J Thorac Cardiovasc Surg. 2014;148:1512-8.

24. Rood KL, Teele SA, Barrett CS, Salvin JW, Rycus PT, Fynn-Thompson F, et al Extracorporeal membrane oxygenation support after the Fontan operation. J Thorac Cardiovasc Surg. 2011;142:504-10.

25. Horne D, Conway J, Rebeyka IM, Buchholz H. Mechanical circulatory support in univentricular hearts: current management. Semin Thorac Cardiovasc Surg Pediatr Card Surg Annu. 2015;18:17-24.

26. Morales DL, Adachi I, Heinle JS, Fraser CD Jr. A new era: use of an intracorporeal systemic ventricular assist device to support a patient with a failing Fontan circulation. J Thorac Cardiovasc Surg. 2011;142:e138-40.

27. Adachi I, Williams E, Jeewa A, Elias B, McKenzie ED. Mechanically assisted Fontan completion: a new approach for the failing Glenn circulation due to isolated ventricular dysfunction. J Heart Lung Transplant. 2016;35:1380-1. 